\title{
Anti-virus properties of titanium nano-particles
}

\author{
Derevianko S. ${ }^{1}$, Vasylchenko A. ${ }^{2}$ \\ Institute of Agricultural Microbiology and Agro-industrial Production of NAAS \\ 97 Shevchenka Str., Chernihiv, 14027, Ukraine \\ e-mail: ${ }^{1}$ biopreparat@i.ua, ${ }^{2}$ top.leader.number.1@gmail.com \\ ORCID: ${ }^{1} 0000-0002-9409-2473,{ }^{2} 0000-0003-2263-8702$
}

Goal. To study the influence of antiviral properties of titanium (Ti) nano-particles (NP) on the reproduction of plant and animal viruses. Methods. Analysis of literature sources, virological, serological, instrumental, and statistical. Results. It was found that the studied preparations contain spherical TiNP with sizes from 2 to 81 $\mathrm{nm}$. Experiments were performed to determine the antiviral activity of TiNP against the strain Teschovirus $A$ of the first serotype (PTV1) Dniprovskyi 34, and the necrotic strain Potato virus Y (PVY) ML1 by prophylactic, therapeutic, and virucidal schemes. In the transplanted culture of swine embryonic kidney cells (SEKC), it was found that TiNP showed little antiviral activity, reducing the virus titer in both schemes by only $0.50 \mathrm{lg} \mathrm{TCD} \mathrm{f}_{50} / \mathrm{cm}^{3}$. However, according to the virucidal scheme, it was found that TiNP at $24 \mathrm{~h}$ exposure at the maximum allowable concentration (for SEKC culture $-12.5 \mu \mathrm{g} / \mathrm{cm}^{3}$ ) showed high virucidal activity against virus strain PTV1 Dniprovskyi 34, significantly reducing its infectious titer in SEKC cell culture by $4.46 \mathrm{lg} \mathrm{TCD}_{50} / \mathrm{cm}^{3}$. It was found that TiNP does not have the antiviral activity to PVY in prophylactic and treatment regimens. As a result of the study of the antiviral activity of TiNP according to the virucidal scheme on tobacco plants, it was found that TiNP has high antiviral activity against PVY. Conclusions. TiNP were found to have high antiviral activity against Teschovirus A strain of the first serotype of Dniprovskyi 34, and necrotic strain of PVY ML1, which belongs to the genus Potyvirus of the Potyviridae family. The obtained results convincingly testify to the prospects of development of effective antiviral nano-preparations and the need for a comprehensive study of the effect of TiNP not only on pathogens but also on the body of animals and crops.

Key words: Ti nano-particles, Teschovirus A, Potato virus $Y$, antiviral activity, electron microscopic studies. DOI: https://doi.org/10.31073/agrovisnyk202008-06

Search for substances with antiviral activity and development of new antiviral drugs and disinfectants is one of the primary areas of research in modern virology. The use of biogenic metals in form of nanoparticles (NPs) opens up perscpectives for the creation of new efficient antiviral drugs [1,2].

Analysis of the latest studies and publications. Scientists pay special attention to titanium dioxide $\left(\mathrm{TiO}_{2}\right)$ NPs and nanocomposites based on them in the area of studying the antiviral activity of different nanomaterials. Antiviral activity of $\mathrm{TiO}_{2}$ nanocolloids (NCs) against Avian orthoavulavirus 1 was studied [3]. $\mathrm{TiO}_{2} \mathrm{NCs}$ have shown to damage lipids of viral envelope due to G-Sol reaction [4] and also damage glycoprotein spikes, which disrupts binding of viral particles to susceptible cells and subsequently loss of infectivity [3]. The same mechanisms were shown to be involved in the inactivation of Porcine epidemic diarrhea virus and Transmissible gastroenteritis coronavirus by $\mathrm{Ag} / \mathrm{TiO}{ }_{2} \mathrm{NCs}$ [4].

$\mathrm{TiO}_{2} \mathrm{NPs}$ with size $4-10 \mathrm{~nm}$ exhibit virucidal activity against influenza virus $\mathrm{H}_{3} \mathrm{~N}_{2}$. Electron microscopy has shown the destruction of viral particles by $\mathrm{TiO}_{2} \mathrm{NPs}$ within 30 minutes. Authors suggest that antiviral activity of this nanomaterial can be explained by the direct contact of NPs with viral particles, which leads to the destruction of capsids [5].

It has been also shown that $\mathrm{TiO}_{2} \mathrm{NPs}$ exhibit antiviral activity not only against human and animal viruses, but also against plant viruses. Thus, $\mathrm{TiO}_{2} \mathrm{NPs}$ exhibit antiviral activity against Broad bean stain virus. It is suggested that $\mathrm{TiO}_{2} \mathrm{NPs}$ induce resistance of plants against the virus and block the interaction between the virus and host cells.

However (despite the promising data), the influence of $\mathrm{TiO}_{2} \mathrm{NPs}$ on other viruses is not studied sufficiently. Therefore, studying the antiviral properties of Ti NPs against Picornaviridae and Potyviridae species is topical and has a valuable scientific and industrial importance.

Aim of the study - to study antiviral effect of Ti NPs on reproduction of plant and animal viruses.

Objectives. The strain Dniprovskyi-34, which belongs to genus Teschovirus, species Teschovirus A, serotype Porcine teschovirus 1 (PTV-1), and the necrotic strain ML-1 of Potato virus $Y$, obtained from the collection of viruses of Institute of agricultural microbiology and agro-industrial production of NAAS of Ukraine, were used in the study.

Colloidal solution of citrate-stabilized Ti NPs was obtained from "Nanomaterials and nanotechnologies" LTD from doctor of technical sciences, Kaplunenko V.Gh. The NPs were produced by the method of ablation [7].

Transmissible cell line of embryonic swine kidney (PEKV) was obtained from national medical institute "Institute of experimental and clinical veterinary medicine. Tobacco plants (Nicotiana tabacum L.) were used to study effects of Ti NPs on plant viruses. 
Water suspension of NPs was diluted to concentrations of $125,0 \mu \mathrm{g} / \mathrm{cm}^{3}$ and $25,0 \mu \mathrm{g} / \mathrm{cm}^{3}$ and $\mathrm{pH}$ was neutralized before use. Next, suspensions were autoclaved under the pressure 0,6 atm. within 20 min. Before use, prepared suspension was added to culture medium and buffer solution to proper concentration.

Antiviral activity of Ti NPs against selected viruses was assessed according to prophylactic, treating and virucidal plots of study.

According to prophylactic plot of study either cell culture or tobacco plants were initially treated with suspension of Ti NPs. After 24 hours, the inoculation with viruses was done.

According to treating plot of study - either PEKV cell culture or healthy tobacco plants were infected with the virus and treated with Ti NPs afterwards.

According to virucidal plot of study, virus-containing suspension and suspension of Ti NPs were mixed at 1:1 ratio and incubated at $+4^{\circ} \mathrm{C}$ for 24 hours. After that the inoculant either was added to cell culture or used to inoculate plants.

Refreshment, maintenance and cultivating of the strain Dniprovskyi-34 were done in PEKV cell culture with use of common methods [8]. The titer of the virus was calculated by the Reed-Muench method [9]. The nanoparticles were used the concentration equivalent to threshold limit value (TLV), which is $12,5 \mu \mathrm{g} / \mathrm{cm}^{3}$ for PEKV cell culture [10]. The antiviral activity of NPs was evaluated by the comparison of the titers of the virus. In the case of the titer's decrease by $2,0 \lg _{10} \mathrm{TCD}_{50}$ and more, the therapeutic index $(\mathrm{TI})$ was evaluated. For the evaluation of TI, the minimum effective concentration (MED) was measured. The MED is the concentration at which the NPs decrease the titer of the virus by $1,25-1,5 \lg _{10} \mathrm{TCD}_{50}$ as compared to control. The TI was calculated as TLV to MED ratio.

Two samples Student's method was used to evaluate the significance of the difference between infectious activity of the virus in different variants of the study. The calculated $t$-values were compared with Student's table [11] and their significance was estimated. The calculations were performed in Microsoft Office Excel software.

Antiviral activity of Ti NPs against PVY was measured in vegetational study. Tobacco plants were infected at the stage of $3-4$ leaves by the method of mechanical inoculation with preliminary treatment with carborundum (500-600 mesh).

Inoculum was prepared from the leaves of diseased potato plants with the addition of buffer solution at 1:1 1:3 ratio. Potassium phosphate buffer with $\mathrm{pH} 7,2-7,5$ and molarity $0,01 \mathrm{M}$ has been used. After the inoculation surfaces of leaves was washed with distilled water. Plants were grown in vegetational rooms at the temperature $20-25^{\circ} \mathrm{C}$ and photoperiod 16 hours.

Severity of PVY infection was assessed visually by observable symptoms, by electron microscopy and serological methods. Serological studies were performed using antiserums produced in virology laboratory of Institute of agricultural microbiology and agro-industrial production of NAAS of Ukraine.

Electron microscopy was performed using electron microscope JEOL JEM-1400 (Japan) at Danylo Zabolotny Institute of Microbiology and Virology of NAS of Ukraine. The microscopy was done using grids with formvar coating. Samples were contrasted with $1 \%$ solution of uranyl acetate within $30 \mathrm{~s}$.

Results and their discussion. Electron microscopy showed that samples of Ti NPs contain spherical NPs with size from 2 to $81 \mathrm{~nm}$, which are either free or comprise agglomerates (Fig. 1).

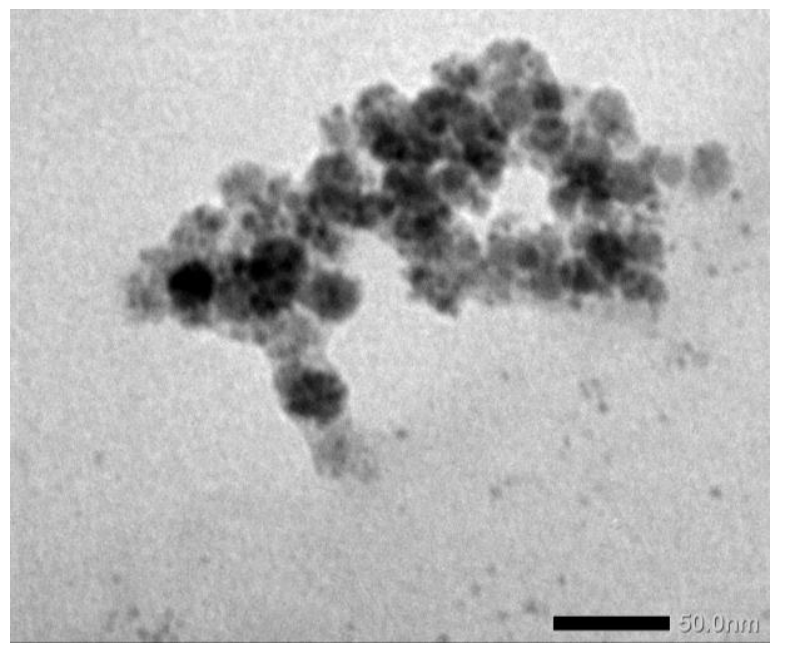

Fig. 1. Electron micrograph of the sample of Ti NPs

Studies of antiviral activity against TV-A were performed according to prophylactic and treating plots of study in PEKV cell culture. It has been shown that Ti NPs exhibit slight antiviral activity, decreasing virus titer by only $0,50 \lg _{10} \mathrm{TCD}_{50} / \mathrm{cm}^{3}$.

Virucidal activity of Ti NPs was studied. Ti NPs have shown high virucidal activity against PTV-1 strain Dniprovskyi-34 at concentration equal to TLV and under exposition of 24 hours, significantly decreasing its infectious titer in PEKV cell culture by $4,46 \lg _{10} \mathrm{TCD}_{50} / \mathrm{cm}^{3}$. 
The dependence of Ti NPs virucidal activity at concentration equal to TLV against PTV-1 strain Dniprovskyi34 on the exposition time was studied. It has been established that the onset of the activity is within 1 hour and that the activity increases with time (table 1). It can be caused by binding of NPs to proteins of viral particles. Thus, silver NPs bind to glycoprotein spikes of HIV-1 viral particles [12]. Despite the fact that picornaviruses unlike HIV-1 are non-enveloped viruses, Ti NPs can bind to proteins of their capsids via similar mechanism. For instance, silver NPs strongly interact with thiol group of cysteine residues in proteins [12]. Therefore, if molecule of protein contains at least one residue of cysteine, NPs bind to it. Local field forces can drive this interaction [13], causing interaction of viral particles not only with silver NPs, but also with NPs of other metals and their oxides. Among other mechanisms of virucidal activity of Ti NPs - reactive oxygen species generation [3, 1415], G-Sol reaction [4], etc.

1. Virucidal activity of Ti NPs against PTV-1 strain Dniprovskyi-34 at the concentration equal to TLV in PEKV cell culture, dependent on exposition time

\begin{tabular}{|c|c|c|c|}
\hline \multirow{2}{*}{ Exposition, hours } & $\mathrm{NPs}$ & $\begin{array}{c}\text { Titer of virus, } \lg _{10} \\
\mathrm{TCD}_{50} / \mathrm{cm}^{3}\end{array}$ & $\begin{array}{c}\text { Difference between titers of virus, } \lg _{10} \\
\mathrm{TCD}_{50} / \mathrm{cm}^{3}\end{array}$ \\
\hline \multirow{2}{*}{1} & $\mathrm{Ti}$ & $3,67 \pm 0,11$ & 2,56 \\
\cline { 2 - 4 } & Control & $6,23 \pm 0,12$ & - \\
\hline \multirow{2}{*}{3} & $\mathrm{Ti}$ & $3,23 \pm 0,10$ & 3,00 \\
\cline { 2 - 4 } & Control & $6,23 \pm 0,12$ & - \\
\hline \multirow{2}{*}{12} & $\mathrm{Ti}$ & $2,77 \pm 0,10$ & 3,46 \\
\cline { 2 - 4 } & Control & $6,23 \pm 0,12$ & - \\
\hline \multirow{2}{*}{24} & $\mathrm{Ti}$ & $1,77 \pm 0,12$ & 4,46 \\
\cline { 2 - 4 } & Control & $6,23 \pm 0,12$ & - \\
\hline
\end{tabular}

Next, MEC and TI for Ti NPs were evaluated. The results of the evaluation are presented in the table 2. I was established that at the concentration equal to TLV Ti NPs decrease the titer of the virus by $4,46 \lg _{10}$ $\mathrm{TCD}_{50} / \mathrm{cm}^{3}$. At the concentration $0,125 \mu \mathrm{g} / \mathrm{cm} 3$ the reduction of the virus titer was $1,23 \mathrm{lg} 10 \mathrm{TCD} \mathrm{T}_{50} / \mathrm{cm}^{3}$. This particular concentration was thought as MAC. Thus, the TI for Ti NPs is 10.

Thus, Ti NPs have high antiviral activity against TV-A and can be recommended for the creation of antiviral drugs, virucidal agents and disinfectants.

Antiviral activity of Ti NPs against strain of PVY ML-1 was assessed using tobacco plants according to prophylactic and treating plots of study. The NPs did not show antiviral activity against PVY according to prophylactic and treating plots of study.

2. Virucidal activity of NPs against PTV-1 strain Dniprovskyi-34 in PEKV cell culture at different concentrations (exposition time 24 hours)

\begin{tabular}{|c|c|c|c|c|}
\hline Substance & $\begin{array}{l}\text { Concentration of } \\
\mathrm{NPs}, \mu \mathrm{g} / \mathrm{cm}^{3}\end{array}$ & $\begin{array}{l}\text { Virus titer, } \lg _{10} \\
\mathrm{TCD} D_{50} / \mathrm{cm}^{3}\end{array}$ & $\begin{array}{c}\text { Differences in titers of virus, } \\
\lg _{10} \mathrm{TCD} \mathrm{D}_{50} / \mathrm{cm}^{3}\end{array}$ & $\mathrm{TI}$ \\
\hline \multirow{6}{*}{$\mathrm{Ti}$} & 12,5 & $1,77 \pm 0,12$ & 4,46 & \multirow{6}{*}{10} \\
\hline & 1,25 & $2,23 \pm 0,14$ & 4,00 & \\
\hline & 0,5 & $2,77 \pm 0,12$ & 3.46 & \\
\hline & 0,25 & $3,50 \pm 0,18$ & 2,73 & \\
\hline & 0,125 & $5,00 \pm 0,14$ & 1,23 & \\
\hline & 0,062 & $6,50 \pm 0,12$ & 0,73 & \\
\hline Control & - & $6,23 \pm 0,12$ & - & - \\
\hline
\end{tabular}

Ti NPs were shown to have high antiviral activity against PVY according to virucidal plot of study (Fig. 2). Test plants remained healthy within 28 days of observation and did not show any signs of PVY infection (Fig. 2a) as well as plants in negative control (Fig. 2b). Serological test and electron microscopy have not revealed the presence of the virus, as well as visual control of observable symptoms.

The inoculation of control tobacco plants with the strain of PVY ML-1 has led to the appearance of the symptoms of necrotic infection (Fig. 2c, d). Vein chlorosis and slight mosaic at the edges of leaves were observed at the beginning of the infection (Fig. 2d). The further development of symptoms was linked to necrosis of leaves, vein necrosis and deformation of leaves, which are specific symptoms of infections caused by necrotic strains of PVY (Fig. 2d). The presence of PVY in these plants was confirmed by serological test and electron microscopy. 


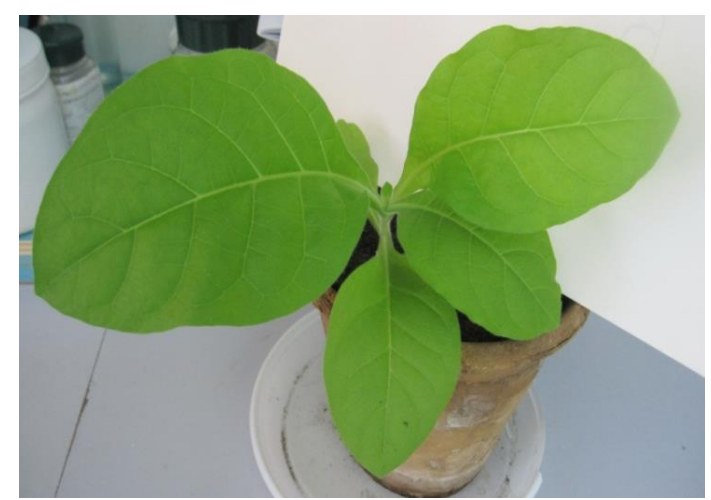

a

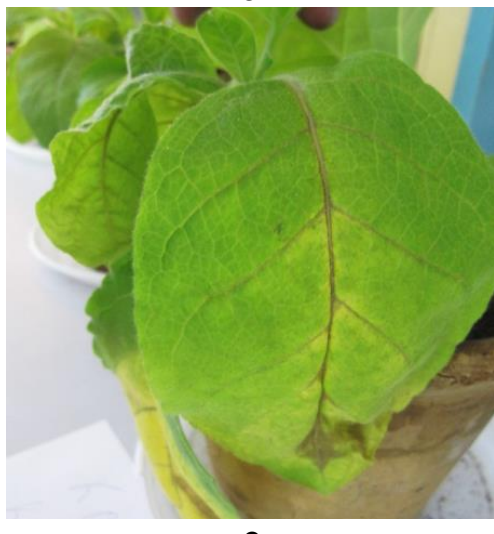

C

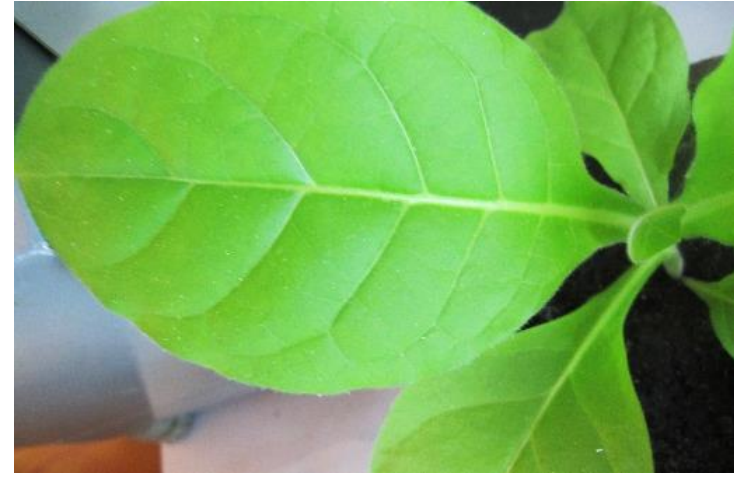

b

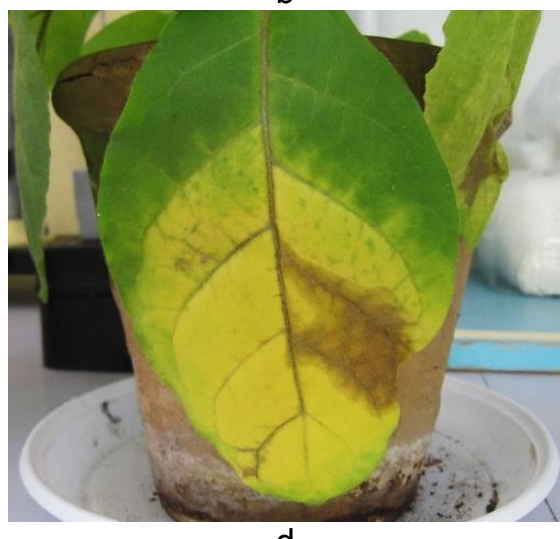

d

Fig. 2. Studies on antiviral activity of Ti NPs against PVY in tobacco plants: a - test plants without symptoms; $b$ - negative control; $c, d$ - symptoms of PVY infection (positive control)

Thus, Ti NPs inactivate PVY in the reaction mixture in vitro according to virucidal plot of study. Coat protein, which forms PVY capsid, contains cysteine residua, to which NPs can bind. Other possible mechanisms are the same as in the case of TV-A: local field forces, reactive oxygen species generation, G-Sol reaction, etc.

\section{Conclusions}

It was established that Ti NPs have high antiviral activity against strain Dniprovskyi-34 of Teschovirus A, serotype Porcine teschovirus 1 and strain ML-1 of Potato virus $Y$, which belongs to genus Potyvirus, family Potyviridae. The results of the study indicate that Ti NPs are perspective for the development of antiviral nanodrugs and that the influence of Ti NPs on both pathogens and organisms of animals and agricultural plants has to be studied thoroughly.

\section{Reference}

1. Galdiero, S., Falanga, A., Vitiello, M., Cantisani, M., Marra, V. \& Galdiero, M. (2011). Silver nanoparticles as potential antiviral agents. Molecules, 16(10), 8894-8918. doi:10.3390/molecules16108894.

2. Rogers, J. V., Parkinson, C. V., Choi, Y. W., Speshock, J. L., \& Hussain, S. M. (2008). A preliminary assessment of silver nanoparticles inhibition of monkeypox virus plaque formation. Nanoscale Res. Lett., 3, 129-133. doi: 10.1007/s11671-008-9128-2.

3. Akhtar, S., Shahzad, K., Mushtaq, S., Ali, I., Rafe, M. H., \& Fazal-ul-Karim, S. M. (2019). Antibacterial and antiviral potential of colloidal Titanium dioxide (TiO2) nanoparticles suitable for biological applications. Materials Research Express, 6(10), 105409. https://doi.org/10.1088/2053-1591/ab3b27.

4. Kim, J.-P., Cho, I.-H., Kim, I.-T., Kim, C.-U., Heo, N.H. \& Suh, S.-H. (2006). Manufacturing of anti-viral inorganic materials from colloidal silver and titanium oxide. Revue Roumaine De Chimie, 51(11), 1121. Corpus ID: 100025589.

5. Kim, J.-P., Cho, I.-H., Kim, I.-T., Kim, C.-U., Heo, N. H., \& Suh, S.-H. (2010). Interaction of titanium dioxide nanoparticles with influenza virus. Nanotechnol. Russia, 5, 417-420. doi:10.1134/s1995078010050174.

6. Elsharkaway, M., \& Derbalah, A. (2019). Antiviral activity of titanium dioxide nanostructures as a control strategy for broad bean strain virus in faba bean. Pest management science, 75(3), 828-834. doi: 10.1002/ps.5185.

7. Kosinov, M. V., \& Kaplunenko, V. Gh. Patent. no. 23550 Ukrajiny, MPK B22F 9/14. Sposib erozijnovybukhovogho dysperghuvannja metaliv [A method of erosive-explosion dispersion of metals]; started 09.02.2007; posted by. 25.05.2007. [In Ukrainian]. 
8. Derevianko, S. V., Bova, T. O., Soroka, V. I., Reshotko, L. M., Bozhok, L. V., Golovko, A. M., \& Katsymon, V. V. (2014). Metodychni rekomendatsii z virusolohichnoho monitorynhu enzootychnoho entsefalomiielitu (khvoroby Teshena) svynei [Methodological recommendations on virological monitoring of enzootic encephalomyelitis (Teschen disease) of pigs]. Chernihiv: Institute of agricultural microbiology and agro-industrial production of NAAS. [In Ukrainian].

9. Reed, L. J., \& Muench, H. (1938). A simple method of estimation of fifty per cent endpoints. The American Journal of Hygiene, 27(3), 493-497. doi:10.1093/oxfordjournals.aje.a118408.

10. Derevianko, S. V., Reshotko, L. M., Dmytruk, O. O., \& Vasylchenko, A. V. (2019). Vyznachennia toksychnosti metalovmisnykh nanochastynok $v$ kulturi klityn ta na bilykh myshakh [Establishment of metal-containing nanoparticles toxicity using cell culture and mice]. Agroecological journal. 2, 91-95. https://doi.org/10.33730/2077-4893.2.2019.174076. [In Ukrainian].

11. The probable error of a mean. (1908). Student. Biometrika, 6(1), 1-25. doi: 10.2307/2331554.

12. Elechiguerra, J. L., Burt, J. L., Morones, J. R., Camacho-Bragado, A., Gao, X., Lara, H. H., \& Yacaman, M. J. (2005). Interaction of silver nanoparticles with HIV-1. Journal of nanobiotechnology, 3(1), 6. doi: 10.1186/1477-3155-3-6.

13. Lozovski, V., Lysenko, V. S., Piatnytsia, V., Scherbakov, O., Zholobak, N. M., \& Spivak, M. Ya. (2012). Physical point of view for antiviral effect caused by the interaction between the viruses and nanoparticles. Journal of Bionanoscience, 6(2), 109-112. doi: 10.1166/jbns.2012.1084.

14. Ma, H., Brennan, A., \& Diamond, S. A. (2012). Photocatalytic reactive oxygen species production and phototoxicity of titanium dioxide nanoparticles are dependent on the solar ultraviolet radiation spectrum. Environmental Toxicology and Chemistry, 31(9), 2099-2107. doi: 10.1002/etc.1916.

15. Kim, H. J., Kim, C. H., Ryu, J. H., Kim. M. J., Park, C. Y., Lee, J. M., Holtzman, M. J., \& Yoon, J. H. (2013). Reactive oxygen species induce antiviral innate immune response through IFN- $\lambda$ regulation in human nasal epithelial cells. American journal of respiratory cell and molecular biology, 49(5), 855-865. doi: 10.1165/rcmb.2013-0003OC. 